\title{
Effects of Lot-Sizing Integration and Learning Effect on Managing Imperfect Items in a Manufacturer-Retailer Chain
}

\author{
Yu-Chung Tsao, ${ }^{1}$ Tsung-Hui Chen, ${ }^{2}$ and Pei-Ying $\mathrm{Wu}^{2}$ \\ ${ }^{1}$ Department of Industrial Management, National Taiwan University of Science and Technology, No. 43, Section 4, \\ Keelung Road, Da'an District, Taipei 106, Taiwan \\ ${ }^{2}$ Department of Marketing \& Distribution Management, National Pingtung Institute of Commerce, 51 Min-Sheng E. Road, \\ Pingtung 90041, Taiwan
}

Correspondence should be addressed to Tsung-Hui Chen; thchen@npic.edu.tw

Received 13 August 2013; Revised 21 October 2013; Accepted 23 October 2013

Academic Editor: Frank Werner

Copyright (C) 2013 Yu-Chung Tsao et al. This is an open access article distributed under the Creative Commons Attribution License, which permits unrestricted use, distribution, and reproduction in any medium, provided the original work is properly cited.

An optimal supply chain performance requires the execution of a precise set of actions, including coordination of the movement of materials, products, and information flows among suppliers, manufacturers, distributors, retailers, and customers. However, a supply chain usually involves several members who are primarily concerned with optimizing their own objectives. This self-serving focus often results in poor channel performance. The present study used the Nash game and the cooperation game in an imperfect production system to investigate the combined effects of lot-sizing integration, learning effect, and an imperfect production process on a manufacturer-retailer channel. This paper also developed a search procedure to solve the problem described, and the optimal properties and a numerical study were conducted to seek structural and quantitative insights into the relationship between the upstream and downstream entities of the supply chain. Numerical results indicated that the cooperation game policy created a higher cost reduction under a wide range of parameter settings.

\section{Introduction}

An adaptable supply chain system usually requires the coordination of materials, products, and information flows among suppliers, manufacturers, distributors, retailers, and customers involved in producing and delivering a final product or service. However, supply chain members are independent actors who focus on optimizing their individual objectives, thereby affecting the performance of other parties in the supply chain. Many studies have demonstrated that game theory is well suited to deal with the interactions among firms and requires that these actions be well coordinated (Fiestras-Janeiro et al. [1], Cachon [2]).

Game theory is a powerful tool for analyzing situations in which the decisions of multiple agents affect each agent's payoff. Game-theoretic models, such as the cooperation in inventory replenishment and production integration between upstream and downstream entities in the supply chain, attract much research. In earlier studies, Monahan [3] Lal and Staelin [4] analyzed the one-vendor one-buyer supply chain with constant demand and price discounts based on order quantity. A Stackelberg game was used to determine the optimal quantity discount schedule from the point of view of the vendor for achieving the joint optimal solution for the vendor and the buyer. J.-M. Chen and T.-H. Chen [5], Zanoni and Zavanella [6], and Tsao [7] use Stackelberg games to discuss similar problems and focused on the singlevendor and single-buyer integration problem by determining the optimal reorder point, order quantity, and number of shipments. They found that channel coordination practices can improve system-wide profits or cost effectiveness. Kohli and Park [8] investigated joint ordering policies as a method to reduce transaction costs between a single seller and a homogeneous group of retailers. They showed that efficient joint lot-sizes are independent of price, and are supported by a range of average-unit prices that permit every possible allocation of transaction cost saving between the buyers and the seller. Cheung and Lee [9] considered a supplier serving multiple retailers located within close proximity and examined the shipment coordination and stock rebalancing effects 
that are linked to vendor-managed inventory programs. They found that the reduction in cost is significant when there are more retailers who can participate in the coordination program. T.-H. Chen and J.-M. Chen [10] proposed several optimization models adopting joint replenishment and channel coordination for a three-level inventory system. These studies primarily explore cost-minimization in the supply chain design, and they do not take a marketing stimulus or promotion into account.

To examine the profit-maximization decision-making phenomenon, Parlar and Weng [11] proposed game-theoretic models of the effects of coordination between the marketing and production departments within two competing firms. Their models showed that coordinating the pricing and production quantity decisions in a firm may lead to a stronger position in terms of increasing expected profits. J.-M. Chen and T.-H. Chen [12] extended the existing work by considering perishable or deteriorative products in a priceendogenous supply chain, which leads to a more practical profit-maximization decision policy in business operations. More recently, Cai et al. [13] studied the impact of different price discount contracts and pricing schemes on the dualchannel supply chain, which includes an online direct channel owned by the supplier and a traditional retail channel. The authors use a game theoretic framework from the perspectives of supplier Stackelberg, retailer Stackelberg, and Nash games to explore the coordination effort in the dualchannel competition. The results of their research showed that simple price discount contracts can effectively improve both the supplier's and retailer's performance. Szmerekovsky and Zhang [14] investigated a Stackelberg game in a decentralized system with the manufacturer as the leader and the retailer as the follower. Unlike to previous research, their model allowed for a continuous level of promotion efforts to be selected by both the manufacturer and the retailer. Their results showed that cost sharing in local advertising does not work well and that it is better for the manufacturer to advertise only nationally and offer the retailer a lower wholesale price.

Tsao [15] considered multiechelon multi-item channels subject to the supplier's credit period and the retailer's promotional effort. He analyzed two trade allowances, cost sharing of the promotion and a cash discount, both of which were designed for coordinating the behavior of the channel partner. Tsao [15] showed that under the coordination scenario the profits for both parties increase when the promotion cost sharing or the cash discount rate is kept within an acceptable range. Chen and Chang [16] investigated the problem of jointly determining the optimal retail price, the replenishment cycle, and the number of shipments for exponentially deteriorating items. Both nonintegrated and integrated policies were investigated while taking into account the combined effects of channel coordination, joint replenishment program, and lot-sizing integration for the two-level supply chain. These realistic considerations made their models more applicable. By incorporating the quantity discount policy into the coordination model, Kamali et al. [17] developed a multiobjective mixed integer nonlinear programming model to coordinate the system of a single buyer and multiple vendors under an all-unit quantity discount policy for the vendors. They developed metaheuristic algorithms to solve the proposed problem, and a numerical example was given to illustrate the behavior of the model. Cachon and Netessine [18] provide a comprehensive overview of the game theory for studying supply chain management problems.

These studies use the unrealistic assumption of the items being perfect in both the production and selling periods. Most production systems produce items of perfect quality as well as imperfect quality. The unit production cost is usually a function of the product reliability parameter. A lower product reliability parameter results in increased development costs of production, reworking, and holding (Sana $[19,20])$. Salameh and Jaber [21] and Maddah and Jaber [22] assume that based on extending the EPQ/EOQ inventory formulation, each lot received contains a percentage of defective items, and has a known probability density function. Their research results showed that the quantity of the economic lot size tends to increase with an increase in the average percentage of imperfect quality item. Ben-Daya and Rahim [23] modeled a multistage production system taking into consideration process inspection and restoration as a means to improve quality. Taking into account rework, Ojha et al. [24] developed three different policies. They showed that the cost of the single-purchase-single-delivery case merges asymptotically with that of the lot-for-lot case which has higher ratios of setup and ordering cost, and increases at a much higher rate than in the other two cases. Jaber et al. [25] extended the work of Salameh and Jaber [21] assuming that the percentage of defective items per lot is reduced based on a learning curve, an assumption which was empirically validated by data from the automotive industry. They showed that the number of defective units, shipment size, and cost reduces as learning increases and follows a form similar to the logistics curve.

Sana [26] proposed an integrated production-inventory model for supplier, manufacturer, and retailer supply chain, which considers perfect and imperfect quality items. The author uses the leader-follower and integrated cases to formulate the supply chain models and determine the optimal production rate and raw material order size for maximizing expected average profit. Sana found that close cooperation can result in more cost-effective production and distribution as well as faster response to customer demand. The integrated profit function is also more profitable compared to the profit of the whole chain by the Stackelberg approach. Tsao et al. [27] extended the traditional production model by considering reworking the imperfect items and trade credit to reflect realistic situations. Unlike previous models, their model calculated the interest earned based on the retail price. The authors developed an easy-to-use algorithm to solve the above described problem, and provided numerical examples to illustrate the influence of interest charged, interest earned, and the impact of the percentage of imperfect items on both production and total cost. Das Roy et al. [28] extended Maddah and Jaber's [22] model by allowing the occurrence of shortages at the end of an order cycle. Optimal shortage period, optimal lot size, and expected average profit for the model are developed for both finite and infinite time horizons. Sana [29] extended the pricing 
policy for fishery and poultry. His model contributed in several ways, considering the demand rates of both foods and the effect of inflation and the time value of money on costs and profits. Pal et al. [30-32] and Sana [33] developed three-layer supply chain models considering the impacts of perfect and imperfect quality items, production reliability, and rework process. They determined the business strategies such as optimal production time, raw material order size, idle times in different sectors, and number of shipments for each of the supply chain members.

This body of research indicates that most industries have shifted from isolated decision-making to a collaborative decision alliance due to increasing competitive pressure, shortened life-cycle products, rigorous quality demands, and quicker response requirements. Sarkar et al. [34], Roy et al. [35], and Pal et al. [36] extended previous studies by investigating an economic production lot size model under system process deterioration and uncertain demand assumption. They developed the optimal buffer inventory, product reliability, and production rate for maximizing total profits or minimizing total costs. In an uncertain demand market setting, Sana [37] generalized the framework for order quantity when sales price and promotional costs are shared by the manufacturer and the retailer. Sana [37] also demonstrated how the coordinating contract of incentives controls the performance of the whole supply chain.

The remainder of this study is organized as follows. Section 2 outlines the problem and summarizes the necessary assumptions and notations. In Section 3, we develop the mathematical models for both the Nash game and the cooperation game policies and provided the optimal properties of the underlying problem. In Section 4, we conduct an extensive numerical study. It provides the reader with qualitative insight into the structure of the proposed models and analyzes the sensitivity of the solutions in relation to the major parameters. Finally, conclusions are drawn in Section 5 .

\section{Assumptions and Notations}

To explore the connection between the decisions made by enterprises in their self-interest, this paper adopted a Nash game and a cooperation game model. These models were used to investigate the combined effects of lot-sizing integration, learning effect, and imperfect production for a two-echelon supply chain. The supply chain consists of one manufacturer who produces and sells a homogeneous group of products to one retailer. The retailer replenishes his stocks on an economic order quantity basis and sells $k$ items to the end customers who consume the items at a fixed rate. The manufacturer produces the products in batches at a finite production rate and distributes the products to a retailer in a number of shipments. The manufacturing system considered in this study is imperfect and occasionally produces finished goods along with undesirable items; that is, the finished products contain a percentage of defective items. These items cannot be reworked and must be discarded after the manufacturing period. In order to reflect that the performance of a person or an organization engaged in repetitive work improves with time, the learning effect was taken into account in the models. In the model development, we assume that the total production learning is lost due to a manufacturing interruption between two consecutive setups. Thus, the learning effect is not inherited from the previous production cycle. The production speed of a finished item increases with the increase in familiarity with the work required and the effective use of the tools involved. In this paper, the production and inventory costs were influenced by defective items as well as the learning effect.

Upon completion of the production process, the manufacturer delivers the finished products to the retailer in a number of shipments. Another assumption is that there is no in-transit inventory between the upstream and downstream entities in the supply chain. The production cycle of the manufacturer is a multiple of the replenishment cycle at the retailer, and the procurement cycle of the manufacturer is a multiple of the production cycle.

The costs incurred by the retailer include the inventory cost for holding the finished items, a major set-up cost for placing a replenishment order, and a minor set-up cost for each additional item added into the replenishment. The major set-up cost represents a lump-sum fee for transportation and delivery, regardless of its composition, and the minor setup cost represents order-processing and item-specific warehousing costs, for each specific item in the replenishment. The end items are assumed to belong to the same category or family of products and share a common production facility. Thus, the manufacturer incurs a major cost for setting up the production line and a minor set-up cost for each additional item placed on the production schedule. The inventory holding costs per unit time are similar between distinct items in the same product family and are influenced by the imperfect items and the learning effect. In order to fulfill the requirements of the make-to-stock policy, the manufacturer also incurs major and minor set-up costs for purchasing raw materials from outside vendors in the quantity sufficient to last for exactly an integer multiple of the production cycle.

Under these conditions, the aim of the supply chain is to minimize the channel-wide costs by finding the optimal replenishment cycle of the finished items for the retailer, the optimal number for shipping the finished items, and the raw materials of the manufacturer. Figure 1 illustrates the changes in the inventory levels for the end items and the raw materials stocked by the retailer and the manufacturer. Here, the quantity of purchased raw materials is double that of the production quantity, while the production quantity is three times the retailer's order. All notations used in this paper are defined and summarized in Table 1.

\section{The Model}

In this paper, the cost models for the two-echelon supply chain were derived under the settings of the Nash game and the cooperation game. In the Nash game policy, the objective of each entity within the supply chain is to minimize its own cost. An entity does not take into consideration any 


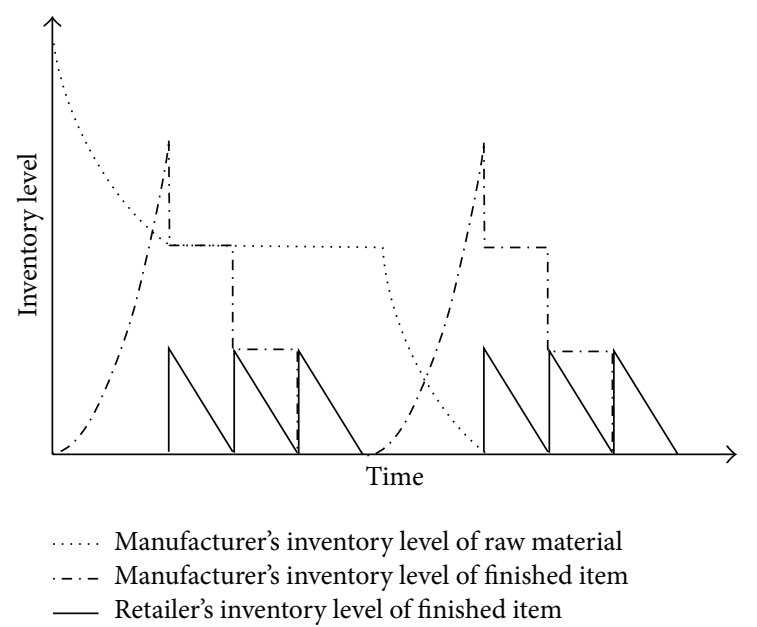

FIGURE 1: Changes in inventory level of the raw materials and the finished items stocked by the retailer and the manufacturer.

cooperative mechanism or damage that may occur to its counterpart as a result of its decisions. On the other hand, in the cooperation game, the entities jointly determine the common optimal replenishment cycle of the finished items, the number of shipments of the finished items, and their raw material needs, with the aim of minimizing the channel-wide cost. We will first demonstrate the model of the Nash game policy and then present the cooperation game policy.

3.1. The Nash Game. In the Nash game model, the manufacturer and the retailer have the same decision-making power. They simultaneously and noncooperatively minimize their own cost, without negotiating with the channel members. In this self-interested decision-making process, the problem facing the retailer is to determine the optimal replenishment cycle for the finished items in order to minimize his own cost. The anticipated costs of the retailer include a major replenishment set-up cost due to lump-sum charges for transportation and delivery, a minor set-up cost for order processing, warehousing expenses, and inventory holding cost. Thus, the cost model of the retailer under the Nash game can be expressed as follows:

$$
\mathrm{TC}_{N, R}=\sum_{i=1}^{k} \mathrm{TC}_{i}\left(T_{N, i}\right)=\sum_{i=1}^{k}\left(\frac{\left(R+r_{i}\right)}{T_{N, i}}+\frac{h_{i} D_{i} T_{N, i}}{2}\right) .
$$

The optimal replenishment cycle for each item can be obtained by solving the first-order differential equation of the cost model of the retailer. Since the convex property of the cost model of the retailer can be easily verified by taking the second-order derivative of (1) with respect to $T_{i}$ it can be omitted, and, the following expresses the optimal replenishment cycle under the Nash game:

$$
T_{N, i}^{*}=\sqrt{\frac{2\left(R+r_{i}\right)}{h_{i} D_{i}}} .
$$

After receiving the order from the retailer, the manufacturer produces the items in batches to fulfill the retailer's

\begin{tabular}{|c|c|}
\hline \multicolumn{2}{|r|}{ System } \\
\hline$k$ & The number of finished items \\
\hline$i$ & The index of the finished items, $i=1,2, \ldots, k$ \\
\hline$j$ & $\begin{array}{c}\text { The index of the decision policies, } j \in\{N, C\} \text {, } \\
\text { where } N \text { denotes the Nash game policy and } C \\
\text { denotes the cooperation game policy }\end{array}$ \\
\hline$D_{i}$ & $\begin{array}{c}\text { The demand rate of finished item } i \text { in the } \\
\text { marketplace }\end{array}$ \\
\hline $\mathrm{TC}_{j, \mathrm{C}}$ & $\begin{array}{l}\text { Total cost for the channel per unit time under } \\
\text { policy } j\end{array}$ \\
\hline \multicolumn{2}{|r|}{ Manufacturer } \\
\hline$t_{p}$ & Production time for each production cycle \\
\hline$n_{j, i}$ & $\begin{array}{c}\text { The number of shipments of item } i \text { per batch } \\
\text { production run under policy } j\end{array}$ \\
\hline$m_{j, i}$ & $\begin{array}{l}\text { The number of shipments of raw material } i \text { per } \\
\text { batch production run under policy } j\end{array}$ \\
\hline$u_{i}$ & The usage rate of raw material for finished item $i$ \\
\hline$F$ & The major set up cost per production cycle \\
\hline$f_{i}$ & $\begin{array}{l}\text { The minor set up cost for adding finished item } i \\
\text { into the production schedule }\end{array}$ \\
\hline$s_{r i}$ & $\begin{array}{l}\text { The ordering cost of the raw material for finished } \\
\text { item } i \text { per production cycle }\end{array}$ \\
\hline$h_{f i}$ & $\begin{array}{c}\text { The inventory holding cost of finished item } i \text { per } \\
\text { unit time }\end{array}$ \\
\hline$h_{r i}$ & $\begin{array}{l}\text { The inventory holding cost of the raw material for } \\
\text { finished item } i \text { per unit time }\end{array}$ \\
\hline$l$ & $\begin{array}{l}\text { The learning rate in the production line, where } \\
\qquad 0.5<l<1\end{array}$ \\
\hline$b$ & $\begin{array}{l}\text { The learning coefficient, which decreases over the } \\
\text { production time required per unit, } b=\log l / \log 2\end{array}$ \\
\hline$\beta$ & $\begin{array}{c}\text { The production rate of defective items per unit } \\
\text { time }\end{array}$ \\
\hline$\gamma$ & $\begin{array}{l}\text { The time required to produce the first unit of the } \\
\text { production cycle }\end{array}$ \\
\hline$t(x)$ & $\begin{array}{l}\text { The time to produce the } x \text { th unit item of the } \\
\text { production cycle }\end{array}$ \\
\hline $\mathrm{TC}_{j, M}$ & The total cost per unit time under policy $j$ \\
\hline \multicolumn{2}{|r|}{ Retailer } \\
\hline$T_{N, i}$ & $\begin{array}{l}\text { The individual replenishment cycle of finished } \\
\text { itemi under the Nash game policy }\end{array}$ \\
\hline$T_{C}$ & $\begin{array}{l}\text { The common replenishment cycle of all finished } \\
\text { items under the cooperation game policy }\end{array}$ \\
\hline$R$ & The major set up cost per replenishment cycle \\
\hline$r_{i}$ & $\begin{array}{l}\text { The minor set up cost for adding finished item } \\
\text { iinto the order }\end{array}$ \\
\hline$h_{i}$ & $\begin{array}{l}\text { The inventory holding cost of finished itemiper } \\
\text { unit time }\end{array}$ \\
\hline $\mathrm{TC}_{j, R}$ & The total cost per unit time under policy $j$ \\
\hline
\end{tabular}

TABLE 1: Summary of notations.

request by adopting a make-to-stock production policy. Thus, the manufacturer's production quantity is an integer multiple of the retailer's ordering quantity. During the production cycle, each batch of item $i$ is dispatched to the retailer in $n_{N, i}$ shipments. This results in a major set-up cost for 
restarting the manufacturing line, a minor set-up cost for each additional item being produced in the line, and an inventory holding cost for the finished items. In addition, the manufacturer incurs inventory holding and ordering costs for the raw materials needed to produce the finished items. Under Wright's [38] learning curve setting, the time to produce $x$ th unit item is a power function and can be represented by

$$
t(x)=a x^{b}
$$

where $\alpha$ is the time to produce the first unit, $x$ is the production count, and $b$ is the learning curve exponent. The learning effect indicates that the time required to perform a task declined at a decreasing rate as experience with the task increased (Hackett 39, Towill 40). The learning effect curve was first proposed by Wright [38], who formulated the relations between the learning variables in quantitative form. Many researchers have compared a number of learning models and concluded that Wright's learning curve model is a good method for general use since it nicely fills a wide range of observed data. This paper uses a similar learning curve model of previous studies to obtain the quantity the manufacturer needs to produce. Based on the above, the cumulative time to produce $n_{j, i} Q_{i}$ units of item $i$ during the production cycle can be expressed as

$$
\begin{aligned}
t_{p} & =t(1)+t(2)+\cdots+t\left(n_{j, i} Q_{i}\right) \\
& =\alpha+\alpha 2^{b}+\alpha 3^{b}+\cdots+\alpha\left(n_{j, i} Q_{i}\right)^{b} \\
& =\alpha \sum_{x=1}^{n_{j, i} Q_{i}} x^{b} .
\end{aligned}
$$

For the sake of convenience, we take the approximation value of (4) and express it as follows:

$$
t_{p} \approx \int_{0}^{n_{j, i} Q_{i}} \alpha x^{b} d x=\frac{\alpha\left(n_{j, i} Q_{i}\right)^{b+1}}{(1+b)}
$$

The production quantities of the manufacturer of item $i$ can be obtained as follows:

$$
n_{j, i} Q_{i}=\left(\frac{(b+1) t_{p}}{\alpha}\right)^{1 /(b+1)}
$$

The change in the inventory level for the finished item $i$ is the result of a combination of production, learning, and defects during the production cycle and can be expressed by the following equation:

$$
I_{f, i}(t)=\left(\frac{(1+b) t}{\alpha}\right)^{1 /(1+b)}-\beta t \quad \text { for } 0 \leq t \leq t_{p}
$$

In each production cycle, the inventory holding cost per unit time of the finished item $i$ can be written as follows:

$$
\begin{gathered}
\left(\frac{h_{f i}}{n_{N, i} T_{N, i}}\right)\left(\int_{0}^{t_{p}} I_{f, i}(t) d t+\frac{n_{N, i}\left(n_{N, i}-1\right) T_{N, i}^{2} D_{i}}{2}\right) \\
=\left(\frac{h_{f i}}{n_{N, i} T_{N, i}}\right) \\
\quad \times\left(\frac{\left(((1+b) / \alpha)^{1 /(b+1)}(1+b) t_{p}^{(2+b) /(1+b)}\right)}{(2+b)}\right) .
\end{gathered}
$$

In this context, the total cost for all finished items and all raw materials per unit time of the manufacturer can be expressed as follows:

$$
I_{r, i}(t)=\left(\frac{(1+b) t}{\alpha}\right)^{-1 /(1+b)}-\beta t \quad \text { for } 0 \leq t \leq n_{N, i} m_{N, i} T_{N, i}
$$

In this context, the total cost for all finished items and all raw materials per unit time of the manufacturer can be expressed as follows:

$$
\begin{aligned}
& \mathrm{TC}_{N, M} \\
& =\sum_{i=1}^{k}\left(\frac{h_{f i}}{n_{N, i} T_{N, i}}\right) \\
& +\left(\frac{\left(((1+b) / \alpha)^{1 /(b+1)}(1+b) t_{p}^{(2+b) /(1+b)}\right)}{(2+b)}-\frac{\beta t_{p}^{2}}{2}\right) \\
& +\frac{\left(F+f_{i}\right)}{\left(n_{N, i} T_{N, i}\right)}+\frac{h_{f i}\left(n_{N, i}-1\right) T_{N, i} D_{i}}{2}+\frac{S_{r i}}{m_{N, i} n_{N, i} T_{N, i}} \\
& +\left(\frac{h_{r i}}{n_{N, i} T_{N, i}}\right)\left(\frac{((1+b) / \alpha)^{1 /(b+1)}(1+b) t_{p}^{b /(1+b)}}{b}\right) \\
& +\left(\frac{h_{r i}\left(m_{N, i}-1\right) u_{i} D_{i} n_{N, i} T_{N, i}}{2}\right) .
\end{aligned}
$$

In the Nash game decision process, the retailer determines the optimal replenishment cycle of finished item $i$, and the manufacturer determines the optimal number of shipments of the finished items and the raw materials required with the aim of minimizing their own costs. The following lemma provides the analytic form and the optimality of the solutions for the manufacturer. 
Lemma 1. For a given replenishment cycle $T_{N, i}$, the optimal number of shipments $n_{N, i}^{*}$ for finished item $i$ is

$$
\begin{aligned}
n_{N, i}^{*}=\left\lceil\left(\frac{-1}{2}\right)+\right. & \left(\frac{1}{2}\right)+4 C^{-1} T_{N, i}^{-2} \\
& \left.\left.\times\left(A+B+F+f_{i}+\left(\frac{S_{r i}}{m_{N, i}}\right)\right)\right)^{1 / 2}\right] .
\end{aligned}
$$

Proof. Please see appendix.

The optimality of the integer multiple number of shipments of raw materials also can be verified by the method shown above and may thus be omitted. The analytic form of the optimal number of shipments for each raw material can be expressed as follows:

$$
m_{N, i}^{*}=\left\lceil\left(\frac{-1}{2}\right)+\left(\left(\frac{1}{2}\right)+8 S_{r i}\left(T_{N, i}^{2} h_{i} u_{i} D_{i} n_{N, i}^{2}\right)^{-1}\right)^{1 / 2}\right\rceil .
$$

The cost model of the supply chain under the Nash game model can be obtained by summing (1) and (10) and can be expressed as follows:

$$
\mathrm{TC}_{N, C}=\mathrm{TC}_{N, R}+\mathrm{TC}_{N, M}
$$

3.2. The Cooperation Game Model. Here, we focus on a cooperative game model in which both the manufacturer and the retailer agree to share business information with each other, try not to interfere with their counterpart's profits through any of their decisions, and jointly make decisions that will minimize the total channel cost. In this decision policy, the anticipated cost of the channel as a whole may be written as

$$
\begin{aligned}
& \mathrm{TC}_{C, C}=\sum_{i=1}^{k}\left(\frac{\left(R+r_{i}\right)}{T_{C}}+\frac{h_{i} D_{i} T_{C}}{2}\right. \\
&+\left(\frac{\left(F+f_{i}\right)}{n_{C, i} T_{C}}+\frac{A}{n_{C, i} T_{C}}+\frac{h_{f i} T_{C} D_{i}\left(n_{C, i}-1\right)}{2}\right. \\
&\left.\left.+\frac{S_{r i}}{m_{C, i} n_{C, i} T_{C}}\right)+\frac{B}{m_{C, i} T_{C}}+\frac{n_{C, i} T_{C} E}{2}\right),
\end{aligned}
$$

where

$$
\begin{gathered}
A=h_{f i}\left(\frac{\left((1+b) t_{p}^{(2+b) /(1+b)}((1+b) / \alpha)^{1 /(1+b)}\right)}{(2+b)}-\frac{\beta t_{p}^{2}}{2}\right), \\
B=h_{r i} b^{-1}(1+b) t_{p}^{b /(1+b)}\left(\frac{(1+b)}{\alpha}\right)^{(1+b)}, \\
E=\left(h_{r i} u_{i}\left(m_{C, i}-1\right)\right) D_{i} .
\end{gathered}
$$

Again, since the optimality of the solutions under the cooperation game model is similar to that of the Nash game model, it can be omitted. Using a similar method to the one developed in the Nash game model, the optimal solutions of the replenishment cycle, the number of shipments for each finished item, and the raw materials required can be expressed as follows:

$$
\begin{gathered}
T_{C}^{*}=\sqrt{\frac{2\left(R+r_{i}+\sum_{i=1}^{k}\left(1 / n_{C, i}\right)\left(F+f_{i}+A+B+\left(S_{r i} / m_{C, i}\right)\right)\right)}{\sum_{i=1}^{k}\left(D_{i}\left(h_{i}+h_{f i}\left(n_{n, i}-1\right)\right)+n_{C, i} E\right)}}, \\
n_{C, i}^{*}=\left[-\frac{1}{2}+\left(\frac{1}{2}+4 T_{C}^{-2}\left(D_{i} h_{f i}+E\right)^{-1}\right.\right. \\
\left.\left.\quad \times\left(A+B+F+f_{i}+\frac{S_{r i}}{m_{C, i}}\right)\right)^{1 / 2}\right] \\
m_{C, i}^{*}=\left[-\frac{1}{2}+\left(\frac{1}{2}+4 S_{r i}\left(T_{C}^{2} D_{i} h_{r i} u_{i} n_{C, i}^{2}\right)^{-1}\right)^{1 / 2}\right]
\end{gathered}
$$

\section{Search Procedure}

Since the objective functions proposed in this study involved multiple interplay variables, we develop an iterative search procedure to delineate the optimal solutions of the problems. In the following, we only present the search algorithm for the cooperation game model; the algorithm for the Nash game model follows a similar pattern and has therefore been omitted. The notations used for recording the optimal values of the search algorithm are defined as follows:

loc $\left\{n_{i}\right\}=$ local optimal integer multiple set of shipments for the finished items;

loc $\left\{m_{i}\right\}=$ local optimal integer multiple set of shipments for the raw materials;

loc $T_{C}=$ local optimal replenishment cycle for the finished items;

gol_$\left\{n_{i}\right\}=$ global optimal integer multiple set of shipments for the finished items;

gol_ $\left\{m_{i}\right\}=$ global optimal integer multiple set of shipments for the finished items;

gol_ $T_{C}=$ global optimal replenishment cycle for the finished items;

loc $\mathrm{TC}_{c, c}=$ variable to record the total cost generated by the local minimum;

gol_ $\mathrm{TC}_{c, c}=$ variable to record the total cost generated by the global minimum.

The step-by-step procedure for the search algorithm is summarized below.

Step 1. Let loc $\left\{n_{i}\right\}=\{\emptyset\}$, loc $_{-}\left\{m_{i}\right\}=\{\emptyset\}$, loc $T_{C}=0$, gol_$\left\{n_{i}\right\}=\{\emptyset\}$, gol_$\left\{m_{i}\right\}=\{\emptyset\}$, gol_t $T_{C}=0$, loc $\_$TC $_{c, c}=0$, and gol_ $_{-} \mathrm{TC}_{c, c}=0$. 
Step 2. Start the search from item 1 to $k$. At each item, do the following steps.

(a) Substitute the random sets $\left\{n_{i}\right\}$ and $\left\{m_{i}\right\}$ into (16) and solve it to obtain the corresponding optimal replenishment cycle $T_{C}^{*}$.

(b) Substitute $T_{C}^{*}$ and $m_{C, i}$ obtained in Step 2(a) into (17) and solve it to obtain a set of integer multiples of shipment $\left\{n_{C, i}^{*}\right\}$.

(c) Substitute $T_{C}^{*}$ and $n_{C, i}^{*}$ obtained in Step 2(b) into (18) and solve it to obtain a set of integer multiples of shipment $\left\{m_{C, i}^{*}\right\}$. Then, $T_{C}^{*},\left\{n_{C, i}^{*}\right\}$, and $\left\{m_{C, i}^{*}\right\}$ are substituted into (14) and solve it to obtain the corresponding total cost, $\mathrm{TC}_{\mathrm{C}, \mathrm{C}}$.

(d) Compare the total costs $\mathrm{TC}_{C, C}$ and loc $\mathrm{TC}_{c, c}$. After making this comparison, let loc ${ }_{-} \mathrm{TC}_{c, c}$ denote the minimal total cost; the corresponding optimal replenishment cycle and integer multiples are represented by loc $T_{C}, \operatorname{loc}_{-}\left\{n_{i}\right\}$, and loc $\left\{\left\{m_{i}\right\}\right.$.

(e) Compare the total costs loc ${ }_{-} \mathrm{TC}_{c, c}$ and gol_ $\mathrm{TC}_{c, c}$. After making this comparison, let gol_tC $\mathrm{TC}_{c, c}$ denote the global minimal total cost; the corresponding optimal replenishment cycle and integer multiples are represented by gol_t $T_{C}$, gol_\{ $\left\{n_{i}\right\}$ and gol_ $\left\{m_{i}\right\}$. If the entire items are examined, then go to Step 3; otherwise, go to Step 2(a).

Step 3. Report the optimal solutions: the optimal replenishment cycle $T_{C}^{*}$, the optimal integer multiples $n_{C, i}^{*}$ and $m_{C, i}^{*}$ of each item, and the optimal objective value $\mathrm{TC}_{C, C}^{*}$, and terminate the search procedure.

\section{The Numerical Study}

The decision-making policies proposed in this study can be applied in solving the integration of inventory lot-sizing and replenishment management problem for the supply chain that involves one retailer and one manufacturer. In this section, a numerical study provides a qualitative insight into the interplay between lot-sizing integration, the learning effect, and the imperfect production process, with a particular focus on the effects of cost improvements on the manufacturer, the retailer, and the entire channel under different parameter settings. Consider the case of a retailer who requires three different items from a manufacturer. The number of items demanded by the retailer are assumed to be 3600,2800 , and $3400 /$ month, respectively. The raw material usage per unit for each finished item is $0.3,0.18$, and 0.2 , respectively. The major set-up cost for each order placed by the retailer is $\$ 320$. The minor set-up costs of the items are $\$ 22, \$ 20$, and $\$ 28$, respectively. The costs of holding the items are $\$ 1.6, \$ 1.3$ and $\$ 1.9 /$ month, respectively. The manufacturer's major set-up cost for each production run is $\$ 140$, while the minor set-up costs of the items are $\$ 36, \$ 30$, and $\$ 38$, respectively. The raw materials' ordering costs are $\$ 36, \$ 30$, and $\$ 38$, respectively. The costs of holding the items are $\$ 0.72, \$ 0.62$, and $\$ 0.8 /$ month, respectively. The costs of holding the raw materials are $\$ 0.41, \$ 0.36$, and $\$ 0.58 /$ month, respectively. Finally, the learning rate, the percentage rate of defective items, and the time required to produce the first unit during the production cycle are $82 \%, 8 \%$, and 0.003 day/unit, respectively.

The first experiment was performed to analyze the behaviors of the channel-wide costs with respect to the number of shipments of raw materials and finished items under the Nash game policy and the cooperation game policy. Figures 3 and 4 show that the cooperation game model results in a greater cost improvement than for the Nash game model under a wide range of parameter settings. Figures 3 and 4 show that the surfaces of the channel-wide costs are convex in the number of shipments of raw materials under both policies. The small number of finished items shipped under the Nash game policy enables it to generate a greater cost saving for the whole supply chain.

The purpose of the second experiment was to investigate the sensitivity of the effects of cost improvement on the whole channel with respect to the major parameters, including $R, t_{p}$, $b, \gamma, \beta$, and $F$. The experiment was performed by changing the above parameters up to $\pm 60 \%$ from their basic settings. The numerical results obtained from the Nash game model were used as the baseline to compute the improvements as a result of the cooperation game model. Table 2 shows the effects of cost improvement after varying the parameters. Based on the results of Table 2, we found that the cooperation game policy created a higher cost improvement than the Nash game policy under a wide range of parameter settings, and that the channel-wide costs of both game policies are highly sensitive to the learning coefficient, the time required to produce the first unit, and the major set-up cost of the manufacturer. Table 2 also shows that the cost improvement under the cooperation game policy decreases as the learning coefficient and the time required to produce the first unit increase.

\section{Conclusions}

This study dealt with the problem of determining the optimal replenishment cycle, the optimal number of shipments of the raw materials, and the finished items for a manufacturerretailer chain with an imperfect production system. During the imperfect production period, the inventory holding costs were influenced by the defective items and the learning effect. Both the Nash game policy and the cooperation game policy were developed taking into consideration the effects of lot-sizing integration, the imperfect production process, and the learning effect, providing structural and quantitative insights into these research streams, as well as improving the applicability of the proposed models. This paper also developed a search procedure to solve the problem described and demonstrated the optimality of the solutions. The numerical study showed that the cooperation game policy is always superior to the Nash game policy in terms of cost improvement and that the channel-wide costs of both game policies are highly sensitive to the learning coefficient, the time required to produce the first unit, and the major setup cost of the manufacturer. 
TABLE 2: Summary of the sensitivity analysis of the parameters on the cost improvement.

\begin{tabular}{|c|c|c|c|c|c|c|c|}
\hline Percentage change of $R$ & $\mathrm{TC} n$ & $\mathrm{TC} c$ & Cost improvement (\%) & Percentage change of $t_{P}$ & $\mathrm{TC} n$ & $\mathrm{TC} c$ & Cost improvement (\%) \\
\hline-60 & 12642 & 11464 & $9.32 \%$ & -60 & 12283 & 11078 & $9.81 \%$ \\
\hline-40 & 12516 & 11328 & $9.49 \%$ & -40 & 12278 & 11072 & $9.82 \%$ \\
\hline-20 & 12390 & 11192 & $9.67 \%$ & -20 & 12272 & 11065 & $9.84 \%$ \\
\hline 20 & 12138 & 10920 & $10.03 \%$ & 20 & 12254 & 11043 & $9.88 \%$ \\
\hline 40 & 12012 & 10784 & $10.22 \%$ & 40 & 12236 & 11024 & $9.91 \%$ \\
\hline 60 & 11886 & 10648 & $10.42 \%$ & 60 & 12218 & 10996 & $10.00 \%$ \\
\hline Percentage change of $b$ & $\mathrm{TC} n$ & $\mathrm{TC} c$ & Cost improvement (\%) & Percentage change of $\gamma$ & $\mathrm{TC} n$ & $\mathrm{TC} c$ & Cost improvement (\%) \\
\hline-60 & 12240 & 10082 & $17.63 \%$ & -60 & 12217 & 9472 & $22.47 \%$ \\
\hline-40 & 12244 & 10312 & $15.78 \%$ & -40 & 12243 & 10151 & $17.09 \%$ \\
\hline-20 & 12259 & 10621 & $13.36 \%$ & -20 & 12252 & 10527 & $14.08 \%$ \\
\hline 20 & 12278 & 11510 & $6.26 \%$ & 20 & 12282 & 11857 & $3.46 \%$ \\
\hline 40 & 12300 & 11702 & $4.86 \%$ & 40 & 12303 & 12107 & $1.59 \%$ \\
\hline 60 & 12346 & 11885 & $3.73 \%$ & 60 & 12706 & 12646 & $0.47 \%$ \\
\hline Percentage change of $\beta$ & $\mathrm{TC} n$ & $\mathrm{TC} c$ & Cost improvement (\%) & Percentage change of $F$ & $\mathrm{TC} n$ & $\mathrm{TC} c$ & Cost improvement (\%) \\
\hline-60 & 12245 & 11050 & $9.76 \%$ & -60 & 12714 & 12590 & $0.98 \%$ \\
\hline-40 & 12251 & 11052 & $9.79 \%$ & -40 & 12564 & 12212 & $2.80 \%$ \\
\hline-20 & 12258 & 11054 & $9.82 \%$ & -20 & 12414 & 11634 & $6.28 \%$ \\
\hline 20 & 12270 & 11058 & $9.88 \%$ & 20 & 12114 & 10478 & $13.51 \%$ \\
\hline 40 & 12277 & 11060 & $9.91 \%$ & 40 & 11964 & 9900 & $17.25 \%$ \\
\hline 60 & 12283 & 11062 & $9.94 \%$ & 60 & 11814 & 9322 & $21.09 \%$ \\
\hline
\end{tabular}

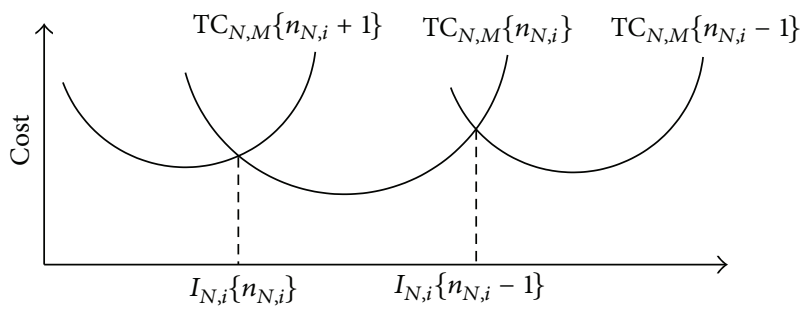

FIGURE 2: The cost function of the manufacturer under the different sets of the shipping numbers of finished items.

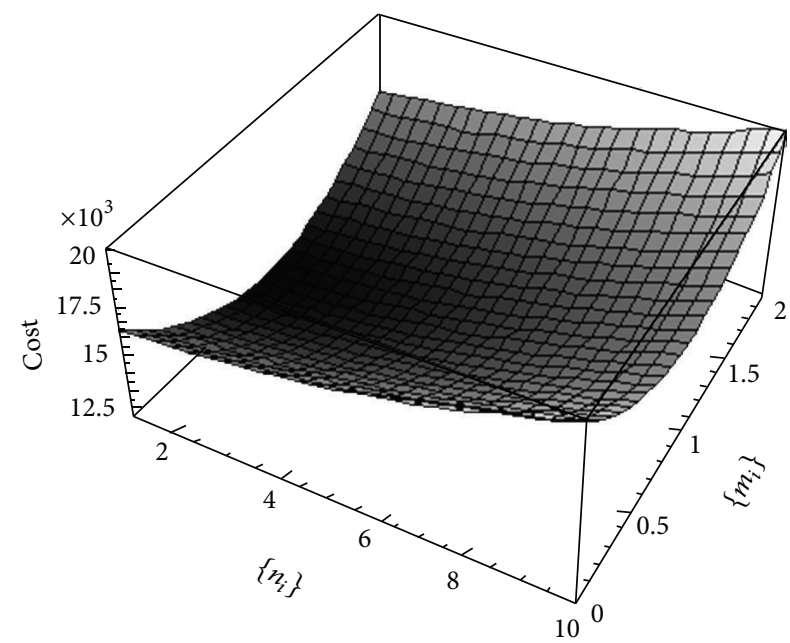

FIGURE 3: The behavior of the channel-wide cost with respect to $n_{i}$ and $m_{i}$ under the Nash game policy.

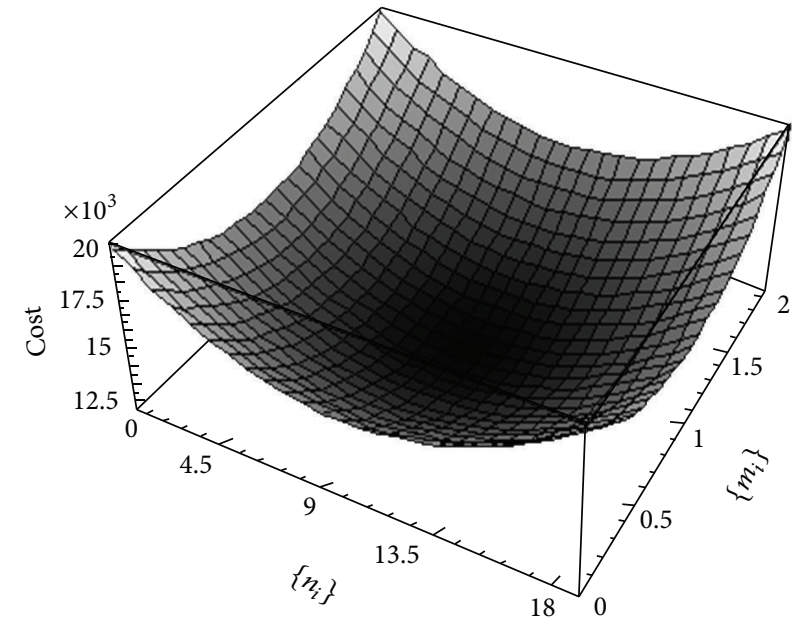

FIgURE 4: The behavior of the channel-wide cost with respect to $n_{i}$ and $m_{i}$ under the cooperation game policy.

The numerical study in this paper showed that the cooperation game policy provides a greater cost improvement than the Nash game model under a wide range of parameters settings. However, the cooperation game policy may increase the cost to the retailer, and it is obvious that the retailer would not accept such policies, although channelwide performance, as a whole, is better. To compensate the retailer for his loss and persuade the damaged entity to accept the cooperation game model, a saving-sharing contract, such as a quantity discount schedule, may be an acceptable mechanism for coordinating channel members. 
The major contribution of this study is its investigation of the combined effects of lot-sizing integration, learning effect, and imperfect production processes on a manufacturer-retailer channel. The subjects of the coordination mechanism or the saving-sharing contract are not included in this study and are worth exploring in the future. The manufacturing system is assumed to be imperfect and to occasionally produce finished goods that are defective. These defective items cannot be reworked and are to be discarded after the manufacturing period. In order to eliminate waste and effectively control the cost of manufacturing, the reworking of these defective items should be investigated in the future.

\section{Appendix}

In the appendix, we provide the optimal values of the replenishment cycle and the optimal number of shipments, which can minimize the cost functions. The derivation of optimal solutions for each item is also given.

For a given replenishment cycle $T_{N, i}$, the optimal number of shipments $n_{N, i}^{*}$ for finished item $i$ is

$$
\begin{aligned}
n_{N, i}^{*}=\lceil & \left(\frac{-1}{2}\right)+\left(\left(\frac{1}{2}\right)\right. \\
& \left.\left.+4 C^{-1} T_{N, i}^{-2}\left(A+B+F+f_{i}+\left(\frac{S_{r i}}{m_{N, i}}\right)\right)\right)^{1 / 2}\right\rceil .
\end{aligned}
$$

Proof. For a given replenishment cycle, the optimal number of shipments of the finished item $i$ can be derived as follows. Since the derivation of the optimal number of shipments of the cooperation game model is similar to that of the Nash game model, we derived this property from the Nash game model only and omitted the cooperation game model. As shown in Figure 2, the cost function of the manufacturer has a different shape when given different sets of shipping numbers for the finished items. The intersection of the two consecutive cost curves, $\mathrm{TC}_{N, M}\left\{n_{N, i}\right\}$ and $\mathrm{TC}_{N, M}\left\{n_{N, i}+1\right\}$, is defined as $I_{N, i}\left\{n_{N, i}\right\}$, where $\left\{n_{N, i}\right\}$ denotes a set of shipping numbers of the finished items. The intersection provides information on the value of $T_{N, i}$ to which the number of shipments, $n_{N, i}$, should be altered to obtain the optimal value of $\mathrm{TC}_{N, M}$. The closed form of the intersection can be located by setting the result of the difference of $\mathrm{TC}_{N, M}\left\{n_{N, i}\right\}$ and $\mathrm{TC}_{N, M}\left\{n_{N, i}+1\right\}$ to zero.

Consider the following:

$$
\begin{aligned}
I_{N, i}\left\{n_{N, i}\right\}=\left(2\left(n_{N, i}\left(n_{N, i}+1\right) C^{-1}\right)\right. \\
\left.\times\left(F+f_{i}+\frac{S_{r, i}}{m_{N, i}}+A+B\right)\right)^{1 / 2},
\end{aligned}
$$

where

$$
\begin{gathered}
A=h_{f i}\left(\frac{\left((1+b) t_{p}^{(2+b) /(1+b)}((1+b) / \alpha)^{1 /(1+b)}\right)}{(2+b)}\right. \\
\left.-\frac{\beta t_{p}^{2}}{2}\right), \\
B=h_{r i} b^{-1}(1+b) t_{p}^{b /(1+b)}\left(\frac{(1+b)}{\alpha}\right)^{(1+b)}, \\
C=\left(h_{f i}+h_{r i} u_{i}\left(m_{i}-1\right)\right) D_{i} .
\end{gathered}
$$

As shown in Figure 2, the manufacturer incurs an optimal cost, $\mathrm{TC}_{N, M}\left\{n_{N, i}\right\}$, and a corresponding integer multiple set of shipments, $\left\{n_{N, i}\right\}$, for a replenishment time between $I_{N, i}\left\{n_{N, i}\right\}$ and $I_{N, i}\left\{n_{N, i}-1\right\}$. Using the closed form of the intersection, we have

$$
\begin{aligned}
& \sqrt{2 n_{N, i}\left(n_{N, i}+1\right) C^{-1}\left(F+f_{i}+\frac{S_{r, i}}{m_{N, i}}+A+B\right)} \\
& \leq T_{N, i} \leq\left(\left(2 n_{N, i}\left(n_{N, i}-1\right) C^{-1}\right)\right. \\
&\left.\times\left(F+f_{i}+\frac{S_{r, i}}{m_{N, i}}+A+B\right)\right)^{1 / 2} .
\end{aligned}
$$

Since $n_{N, i}$ is a positive integer, the range of $n_{N, i}$ can be obtained by executing some mathematical operations in (A.4).

Consider the following:

$$
\begin{aligned}
-\frac{1}{2}+\left(\frac{1}{2}+4 C^{-1} T_{N, i}^{-2}\left(A+B+F+f_{i}+\frac{S_{r i}}{m_{N, i}}\right)\right)^{1 / 2} \\
\leq n_{N, i} \leq \frac{1}{2}+\left(\frac{1}{2}+4 C^{-1} T_{N, i}^{-2}\right. \\
\left.\times\left(A+B+F+f_{i}+\frac{S_{r i}}{m_{N, i}}\right)\right)^{1 / 2} .
\end{aligned}
$$

Since the difference between the two inequalities in (13) is equal to 1 , it implies that one integer is between $(-1 / 2)+\left((1 / 2)+4 C^{-1} T_{N, i}^{-2}\left(A+B+F+f_{i}+\left(S_{r i} / m_{N, i}\right)\right)\right)^{1 / 2}$ and $(1 / 2)+\left((1 / 2)+4 C^{-1} T_{N, i}^{-2}\left(A+B+F+f_{i}+\left(S_{r i} / m_{N, i}\right)\right)\right)^{1 / 2}$ or that they are both integers. In either case, taking the entire upper portion of the expression in the left-hand side yields the integer $n_{N, i}$ thereby satisfying (A.5). Therefore, given 
the replenishment cycle, a corresponding optimal number of shipments, $n_{N, i}^{*}$, can be obtained and is given as follows:

$$
\begin{aligned}
n_{N, i}^{*}=\left\lceil\left(-\frac{1}{2}\right)+\left(\left(\frac{1}{2}\right)+4 C^{-1} T_{N, i}^{-2}(A\right.\right. & +B+F+f_{i} \\
& \left.\left.\left.+\left(\frac{S_{r i}}{m_{N, i}}\right)\right)\right)^{1 / 2}\right\rceil .
\end{aligned}
$$

\section{References}

[1] M. G. Fiestras-Janeiro, I. García-Jurado, A. Meca, and M. A. Mosquera, "Cooperative game theory and inventory management," European Journal of Operational Research, vol. 210, no. 3, pp. 459-466, 2011.

[2] G. P. Cachon, "Supply chain coordination with contracts," in Handbooks in Operations Research and Management Science: Supply Chain Management, S. Graves and T. de Kok, Eds., North Holland, 2003.

[3] J. P. Monahan, "A quantity discount pricing model to increase supplier's profits," Management Science, vol. 32, pp. 1177-1185, 1984.

[4] R. Lal and R. Staelin, "An approach for developing an optimal discount pricing policy," Management Science, vol. 30, pp. 15241539, 1984.

[5] J.-M. Chen and T.-H. Chen, "Effects of joint replenishment and channel coordination for managing multiple deteriorating products in a supply chain," Journal of the Operational Research Society, vol. 56, no. 10, pp. 1224-1234, 2005.

[6] S. Zanoni and L. Zavanella, "Single-vendor single-buyer with integrated transport-inventory system: models and heuristics in the case of perishable goods," Computers and Industrial Engineering, vol. 52, no. 1, pp. 107-123, 2007.

[7] Y.-C. Tsao, "Retailer's optimal ordering and discounting policies under advance sales discount and trade credits," Computers and Industrial Engineering, vol. 56, no. 1, pp. 208-215, 2009.

[8] R. Kohli and H. Park, "Coordinating buyer-seller transactions across multiple products," Management Science, vol. 40, no. 9, pp. 1145-1150, 1994.

[9] K. L. Cheung and H. L. Lee, "The inventory benefit of shipment coordination and stock rebalancing in a supply chain," Management Science, vol. 48, no. 2, pp. 300-306, 2002.

[10] T.-H. Chen and J.-M. Chen, "Optimizing supply chain collaboration based on joint replenishment and channel coordination," Transportation Research E, vol. 41, no. 4, pp. 261-285, 2005.

[11] M. Parlar and Z. K. Weng, "Coordinating pricing and production decisions in the presence of price competition," European Journal of Operational Research, vol. 170, no. 1, pp. 211-227, 2005.

[12] J.-M. Chen and T.-H. Chen, "The profit-maximization model for a multi-item distribution channel," Transportation Research E, vol. 43, no. 4, pp. 338-354, 2007.

[13] G. Cai, Z. G. Zhang, and M. Zhang, "Game theoretical perspectives on dual-channel supply chain competition with price discounts and pricing schemes," International Journal of Production Economics, vol. 117, no. 1, pp. 80-96, 2009.

[14] J. G. Szmerekovsky and J. Zhang, "Pricing and two-tier advertising with one manufacturer and one retailer," European Journal of Operational Research, vol. 192, no. 3, pp. 904-917, 2009.
[15] Y.-C. Tsao, "Managing multi-echelon multi-item channels with trade allowances under credit period," International Journal of Production Economics, vol. 127, no. 2, pp. 226-237, 2010.

[16] T. H. Chen and H. M. Chang, "Optimal ordering and policies for deteriorating items in one-vendor multi-retailer supply chain," International Journal of Advanced Manufacturing Technology, vol. 41, pp. 1208-1220, 2010.

[17] A. Kamali, S. M. T. Fatemi Ghomi, and F. Jolai, "A multiobjective quantity discount and joint optimization model for coordination of a single-buyer multi-vendor supply chain," Computers \& Mathematics with Applications, vol. 62, no. 8, pp. 3251-3269, 2011.

[18] G. P. Cachon and S. Netessine, "Game theory in supply chain analysis," in Handbook of Supply Chain Analysis in E-Business Era, D. Simchi-Levi, S. D. Wu, and M. Shen, Eds., Kluwer Academic, New York, NY, USA, 2004.

[19] S. S. Sana, "A production-inventory model in an imperfect production process," European Journal of Operational Research, vol. 200, no. 2, pp. 451-464, 2010.

[20] S. S. Sana, "An economic production lot size model in an imperfect production system," European Journal of Operational Research, vol. 201, no. 1, pp. 158-170, 2010.

[21] M. K. Salameh and M. Y. Jaber, "Economic production quantity model for items with imperfect quality," International Journal of Production Economics, vol. 64, no. 1, pp. 59-64, 2000.

[22] B. Maddah and M. Y. Jaber, "Economic order quantity for items with imperfect quality: revisited," International Journal of Production Economics, vol. 112, no. 2, pp. 808-815, 2008.

[23] M. Ben-Daya and A. Rahim, "Optimal lot-sizing, quality improvement and inspection errors for multistage production systems," International Journal of Production Research, vol. 41, no. 1, pp. 65-79, 2003.

[24] D. Ojha, B. R. Sarker, and P. Biswas, "An optimal batch size for an imperfect production system with quality assurance and rework," International Journal of Production Research, vol. 45, no. 14, pp. 3191-3214, 2007.

[25] M. Y. Jaber, S. K. Goyal, and M. Imran, "Economic production quantity model for items with imperfect quality subject to learning effects," International Journal of Production Economics, vol. 115, no. 1, pp. 143-150, 2008.

[26] S. S. Sana, "A production-inventory model of imperfect quality products in a three-layer supply chain," Decision Support Systems, vol. 50, no. 2, pp. 539-547, 2011.

[27] Y. C. Tsao, T. H. Chen, and S. M. Huang, "A production policy considering reworking of imperfect items and trade credit," Flexible Services and Manufacturing Journal, vol. 23, no. 1, pp. 48-63, 2011.

[28] M. Das Roy, S. S. Sana, and K. Chaudhuri, "An optimal shipment strategy for imperfect items in a stock-out situation," Mathematical and Computer Modelling, vol. 54, no. 9-10, pp. 2528-2543, 2011.

[29] S. S. Sana, "Optimal pricing strategy for livestock of fishery and poultry," Economic Modelling, vol. 29, no. 4, pp. 1024-1034, 2012.

[30] B. Pal, S. S. Sana, and K. Chaudhuri, "A multi-echelon supply chain model for reworkable items in multiple-markets with supply disruption," Economic Modelling, vol. 29, pp. 1891-1898, 2012.

[31] B. Pal, S. S. Sana, and K. Chaudhuri, "Three-layer supply chain-a production-inventory model for reworkable items," Applied Mathematics and Computation, vol. 219, no. 2, pp. 530$543,2012$. 
[32] B. Pal, S. S. Sana, and K. Chaudhuri, "A three layer multiitem production-inventory model for multiple suppliers and retailers," Economic Modelling, vol. 29, pp. 2704-2710, 2012.

[33] S. S. Sana, "A collaborating inventory model in a supply chain," Economic Modelling, vol. 29, pp. 2016-2023, 2012.

[34] B. Sarkar, S. S. Sana, and K. Chaudhuri, "An imperfect production process for time varying demand with inflation and time value of money-an EMQ model," Expert Systems with Applications, vol. 38, no. 11, pp. 13543-13548, 2011.

[35] A. Roy, S. S. Sana, and K. Chaudhuri, "Optimal replenishment order for uncertain demand in three layer supply chain," Economic Modelling, vol. 29, pp. 2274-2282, 2012.

[36] B. Pal, S. S. Sana, and K. Chaudhuri, "A mathematical model on EPQ for stochastic demand in an imperfect production system," Journal of Manufacturing Systems, vol. 32, pp. 260-270, 2013.

[37] S. S. Sana, "Optimal contract strategies for two stage supply chain," Economic Modelling, vol. 30, pp. 253-260, 2013.

[38] T. Wright, "Factors affecting the cost of airplanes," Journal of Aeronautical Science, vol. 3, pp. 122-128, 1936. 


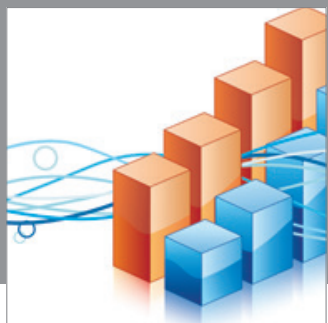

Advances in

Operations Research

mansans

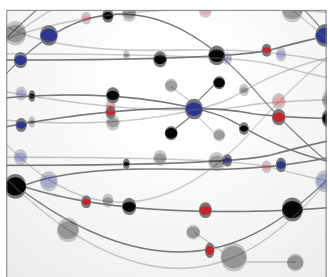

The Scientific World Journal
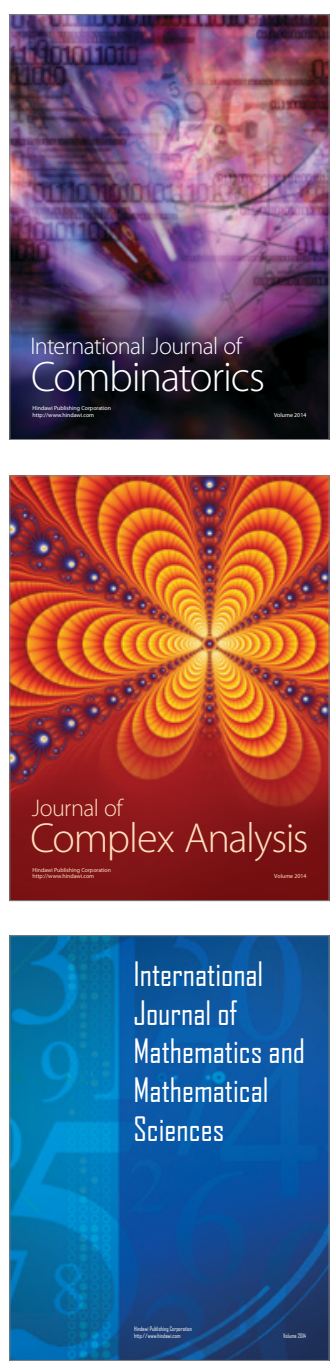
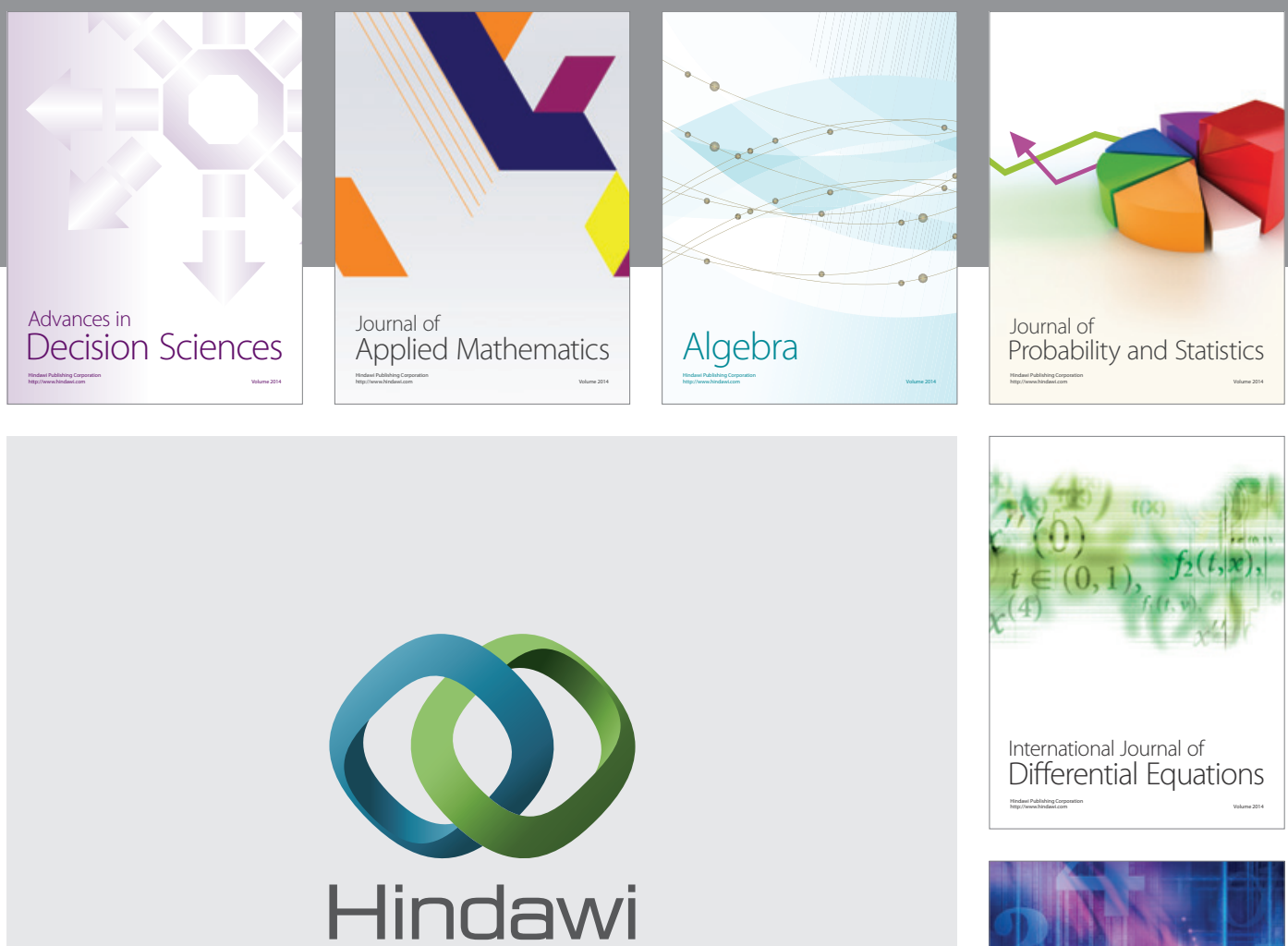

Submit your manuscripts at http://www.hindawi.com
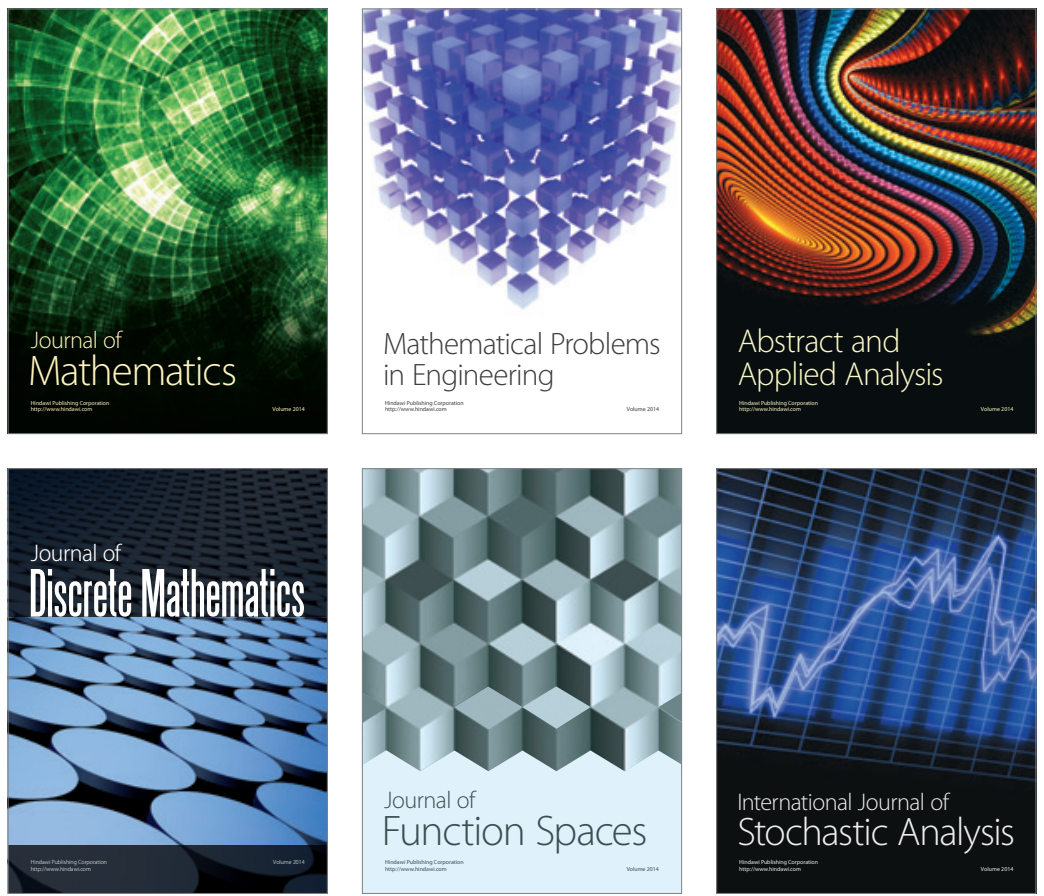

Journal of

Function Spaces

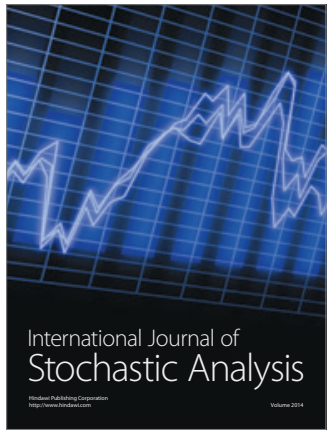

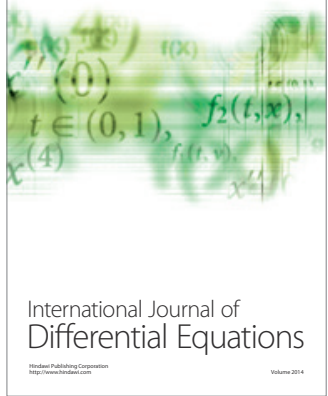
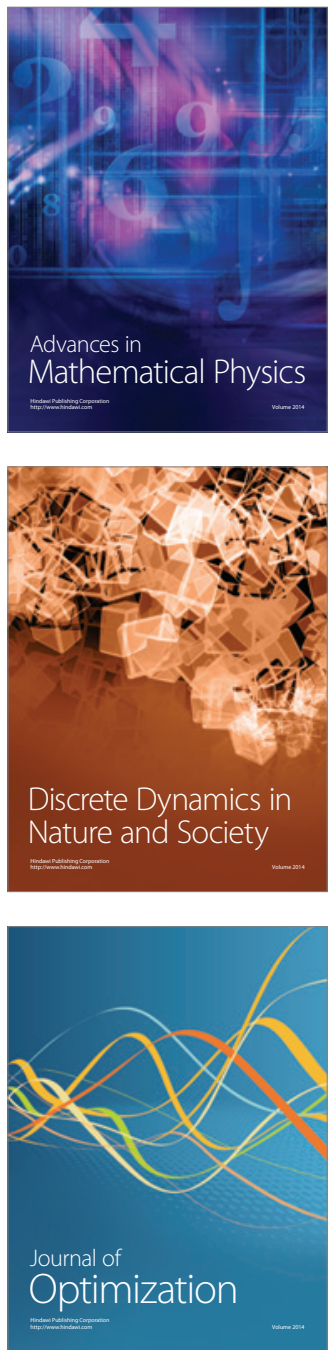